\title{
A Participatory Financial Decision-Making of The Micro Business
}

\section{ZOUITENE Ikram ${ }^{1}$, BENSBAHOU Aziz ${ }^{2}$}

${ }^{1} \mathrm{PhD}$ Scholar in Economics and Management

${ }^{2}$ Professors and Thesis Director

Ibn Tofail University, Faculty of Legal, Economic and Social Sciences

Kenitra, Morocco

\begin{abstract}
Since the owner-managers of TPE occupy a dominant position in their role as the main decision-maker of the company, the financing structure of the company is their personal choice; the decisions that owner-operators make may therefore depend on the characteristics of the owners and the businesses (Michaelas et al., 1999).

In this "new" reality, researchers and financial practitioners recognize the need to solve financial decision problems by going beyond the limits of traditional financial theories.

This new alternative was announced at the end of the 1970s, it was the birth of the theory of behavioral finance, which was launched from the study of Kahneman and Tversky (1979). Over the past 30 years, behavioral finance has become one of the most widely used theories to understand and interpret the behavior of investors and policymakers in making their investment and funding decisions. It is still an emerging field (Kourtidis, Šević and Chatzoglou, 2011), but it has received a lot of attention from professionals and academic staff.
\end{abstract}

This article is a review of the literature on the capital structure of companies, by mobilizing traditional financial theories that help to understand the financial decision-making of VSE leaders.

Keywords: Micro small business, Traditional financial theories, Financial decision-making.

\section{INTRODUCTION}

Very small businesses (VSBs) are the backbone of economic systems and are the main drivers of long-term economic growth. With an estimated contribution of $43.5 \%$ of global employment, VSB are of crucial importance, especially in developing countries (Ayyagari et al., 2011). Despite this importance, VSBs face greater barriers to operation and expansion than medium and large firms. At the forefront of these barriers is the lack of access to external funding for their activities (Beck et al., 2005, 2006).

Because of their heterogeneity and opaque nature, VSBs generally can not reclassify financial markets to raise funds, which makes them largely dependent on domestic financing. The vulnerability of the VSB sector to changing conditions has also become more evident as a result of the global financial crisis of 2008 (OECD, 2015). These difficulties have led researchers and academics to take a closer look at the problems of VSBs access to financing and to seek solutions adapted to their needs and specificities.

Since the owner-managers of TPE occupy a dominant position in their role as the main decision-maker of the company, the financing structure of the company is their personal choice; the decisions that owner-operators make may therefore depend on the characteristics of the owners and the businesses (Michaelas et al., 1999). In this "new" reality, researchers and financial practitioners recognize the need to solve financial decision problems by going beyond the limits of traditional financial theories.

This new alternative was announced at the end of the 1970s, it was the birth of the theory of behavioral finance, which was launched from the study of Kahneman and Tversky (1979). Over the past 30 years, behavioral finance has become one of the most widely used theories to understand and interpret the behavior of investors and policymakers in making their investment and funding decisions. It is still an emerging field (Kourtidis, Šević and Chatzoglou, 2011), but it has received a lot of attention from professionals and academic staff. 


\section{VSB AND FINANCING CONSTRAINTS}

The interest of researchers for the VSB began to emerge only very late compared to its colleagues, the average and the big company. As many authors point out, this is due to the hegemony of big companies whose model had corresponded for a long time to the economic context resulting from Taylorism and the industrial era of the early twentieth century.

Today, in the opinion of all specialists, it is clear that these small structures constitute the major part of the economic fabric, to the point that, as an example, "concerning France, we can notice, as for Europe as a whole, the very high proportion of VSB-SB $(98.76 \%)$ compared to the total number of companies "(Regnault, 2011).

\subsection{Definition and specificity of VSB}

In their attempts to develop definitions of VSB, researchers have opted for different approaches. In his book intitled Very Small Enterprises, Ferrier (2002) distinguishes five main approaches: quantitative; qualitative; international; composite and by technology.

- The quantitative approach: It is to the most commonly used approach in the literature, especially because of the obvious criterion of the size of the VSB which, as its name suggests, necessarily claims to be very small. Also, three main quantitative criteria were used to measure this size. This refers to the number of employees, the turnover and the assets of the company (total capital, including equity).

- The qualitative approach is another angle that offers some possibilities for distinguishing between VSBs and other types of enterprises, although in some cases, as noted by the researchers, this distinction may not be very clear.

a. The type of origin or ownership of the company: Indeed, one of the qualitative criteria that has been developed by researchers like Smith and Miner (1983) or Lorain and Dussault (1988) is the type of origin or ownership of the company. This criterion corresponds to the organizational form. According to these two authors, this form constitutes a distinctive criterion making it possible to differentiate the VSB (but not always).

b. Strategies or managerial objectives: This second criterion has been mentioned by many authors such as Liles (1974); Stanworth and Curran (1976); Filey and Aldag (1978); Cooper and Dunkelgerg (1982); Miller and Friesen (1982), Carland et al. (1984), or Marchesnay (1988) corresponds to the consideration of the strategic choices made by the leaders of the VSB and their relationship with the interests of the latter.

c. The stage of evolution, development or organization of the VSB: Developed by authors like Greiner (1972), Churchill and Lewis (1984) or Vargas (1984), from the concept of life cycle, this criterion focuses on the study of the evolution of the VSB through different phases (creation, survival, success and flight), integrating parameters such as the degree of separation between the VSB and its owner.

- The international approach: The need to apprehend the VSB in an international approach was dictated in particular by the globalization of economies. For example, organizations such as the OECD have addressed the issue of the dissimilarities among countries in the criteria for categorizing firms.

- The composite approach: As its name indicates, the composite approach consists in taking into account all the approaches mentioned above by combining them. Thus, it is the assessment of the quantitative and qualitative data gathered that makes it possible to determine whether or not the VSB is the name that corresponds or not to the company concerned.

The study entitled "SMEs and Globalization" (1997a, 1997b), which the OECD initiated, set out to present a number of criteria facilitating the typology of enterprises, including those of small sizes such as VSBs and to provide precise definitions, with a view to minimizing disparities between countries in this regard.

In Morocco, it is necessary to distinguish between the micro enterprise (1 to 9 employees) and the small enterprise (10 and more). Within micro-enterprises, we have the smallest companies (1 to 3) who are the true micro-enterprises (strictly speaking) and the smaller ones (4 to 5) and especially the very small enterprises (6 to 9 people) (Hamdouch et al., 2004).

\subsubsection{Modes and constraints of financing VSBs}

Although the Moroccan VSBs have several positive qualities and characteristics such as technical know-how, a skilled and professional workforce, etc., the Moroccan VSB suffers from a major constraint which is the "Financing". Today, a large proportion of very small businesses in emerging countries rely on self-financing to meet their financing needs, but the lion's share goes to bank credit. On the other hand, the bank loan remains the most sought-after means by SMEs even if its conditions are a bit 
difficult to satisfy given the problem of guarantees and commitment. The problem of financing remains, at the moment, the most difficult constraint to be solved and which hinders the growth, the competitiveness, the development and the continuity of the Moroccan SME.

The problems are also rooted in the companies themselves: besides the lack of financial information, many business owners, who would otherwise be eligible for credit, are unaware of banking practices and alternative sources of financing, such as leasing and factoring, which is an obstacle to making an optimal financial decision and thus to access to credit. This is a problem of asymmetric information and risk factor design between the banker and the entrepreneur.

These two actors, inextricably linked, must be able to establish a common language so that there is a link between the applicants for capital and the contributors of capital. Thus, considering the importance of the financing problem; the nature, the logic of action, and the behavior of these two actors the SME (mainly family and generally under capitalized) and the bank (mainly commercial), as well as the nature of the apprehension of the risk must be correctly analyzed. ${ }^{1}$

The actual funding needs of PTTs evolve according to the life cycle of the company and according to its sector of activity. Indeed, the creation of a T.P.E requires funds. Once installed, it needs financial services for start-up and working capital and finally in the growth and development phase, the T.P.E. will require financial assistance.

\subsubsection{Formal financing}

By conventional banks: With a banking system almost comparable to that of developed countries, Morocco had at the end of 20152 a large number of commercial banks (29 banks accredited by Bank Al Maghrib). The Moroccan banking landscape has begun to show a particular interest in VSBs3, especially after the launch of the program of support for financing very small, medium and small businesses by the central bank.

Despite this initiative, jointly launched by the central bank and commercial banks, VSBs continue to face serious obstacles to accessing bank credit; a mode of financing that remains by far their preferred mode. Indeed, the figures of Bank Al Maghrib (the Moroccan central bank) reveal that the share of VSBs and SMEs (combined) in loans granted to non-financial companies could not exceed $36 \%$ in 2014 (BAM, 2014).

The reasons for the reluctance of micro-entrepreneurs to bank loans were raised by an old research by SERVET \& LELART (1990), but they are still valid in the Moroccan context. They are essentially summarized in the following 3 points:

$\checkmark \quad$ Illiteracy makes the constitution of the credit file a cumbersome and complex task.

$\checkmark \quad$ Interest rates that are too high, justified (by the banks) by the small size of the financial transactions offered by the banks to very small businesses and the size of the fixed costs related to the study of each loan application.

$\checkmark$ Lack of collateral required by banks in return for a credit agreement.

These constraints led to the emergence of a financial paradigm dedicated exclusively to micro-enterprises and the non-bankable poor.

By the micro-credit institutions: While access to bank loans is subject to conditions that are difficult for microentrepreneurs to reach, the I.M.F. In the context of an imperfect financial market, they have been able to extend their services to this category of agents without losing sight of the constraint of seeking a stability that is the only guarantee of sustainability for their activities (Doumbouya, 2008). Today, MFIs still only partially cover the needs of this PE segment. MFIs mainly target microcredit and the short term. In general, they have suitable products to finance the treasury of income-generating activities (IGAs) and microenterprises (to give an order of magnitude, short-term loans of less than $€ 1,500$ ). This covers some of the needs of small businesses, but only a small part. As the cost of transactions remains high.

\subsubsection{Informal financing}

The use of informal sources of finance is a widespread practice in the poor. This is due, on the one hand, to the nature of their financial need, which is generally limited to small amounts of money to be repaid in the very short term, even at an excessive cost (TANI \& RADI, 2014). The second reason for the development of this funding channel is the lack of collateral requirements, since only the knowledge of the claimant and its proximity are required when agreeing an informal credit. This was confirmed by the results of the studies that highlighted the central and major role of the grocer in smoothing the daily cash flow of Moroccan villagers (GUERIN, MORVANT-ROUX, et al., 2011).

\footnotetext{
${ }^{1}$ Mr. ABDELLAOUI and A. HAOUDI, (2014), "Financing tools and SME development constraints in Morocco", Fez University,
} Morocco 
Several research studies have shown that the success of these informal financial activities is essentially based on the geographical and cultural proximity between the lenders and their clients. Something that justifies once again the role of the grocer among informal lenders. The latter represents an important source of micro credits that we can qualify as being the first competitor of micro-credit associations in rural Morocco.

\subsubsection{Leader as a major player in the VSB}

All the specialists of the VSB agree to consider that what characterizes this type of company is that it centers on its leader who constitutes the central pivot and the person without the presence of which this organization could not exist. (Julien and Marchesnay, 1988, Naro, 1989). It is for this reason that many authors speak of "highly personalized leadership" (Marchesnay, 1988) as the predominant governance modality in the VSB.

Indeed, if there is one aspect that immediately characterizes the VSB, it is certainly the fact that the existence of the latter is, to a great extent, due to a key element: the leader, this character central that often carries alone on his back the heavy responsibilities related not only to the creation and emergence of the VSB, but also and especially its durability.

This same conclusion has already been made before by researchers such as Fallery (1983) or Mintzberg (1984) who also believe that because of the multiple tasks that the leader of the VSB carries out and the extended powers which are his, this The latter is the central pivot of the managerial and decision-making system.

Also, his day-to-day management on all fronts makes him a person "in a situation of over-occupation of activity time. (Marchesnay, 1988).

\section{- Who are the leaders of the VSB?}

Very little known due to the focus of most studies and academic research on large firms, the leaders of very small companies still remain for the vast majority of them in the shadows. And for good reason, data and information on large groups are naturally much more accessible than those relating to very small businesses.

The definition of the leader of the VSB is not an easy thing and this because of the multitude of terms used to designate the function of the individual who is responsible for leading this specific structure in many respects. Indeed, the terms entrepreneur, entrepreneur, manager, manager, boss, etc. are all words used to designate the leader of the VSB.

This diversity of terms, which refer globally to the same reality, but from complementary angles, is not without alluding to the diversity of the aspects relating to the mission of the manager of the one who finds himself compelled to be on all fronts for to be able to sustain his business.

\subsubsection{The contractor}

"SME manager, a job? "(Insights on SMEs $\mathrm{N}^{\circ}$ 8, September 2005, p: 26) Thus, the journal Regard on VSBs titrated its eighth issue devoted to an overview of issues relating to the leader of small business, his profile, his mission, his challenges, etc.

With regard to the question of appellations relating to this specific trade, the term entrepreneur "historically refers to the capitalist merchant who appears in the middle class, synonymous English adventurer and undertaker. Driven by entrepreneurship, he takes risks "((Insights on SMEs $\mathrm{N}^{\circ} 8$, Ibid).

Regarding this first term, relating to the mission of the first person in charge of the VSB, it should be noted that it is this term of entrepreneur, which gave birth to one of the most important notions in the world of business, namely entrepreneurship, which has become a field of research in its own right, having as its object all that is attractive to the creation of enterprises.

Beyond this meaning of the term entrepreneur who essentially stops at the action of creating a company, it should be noted that the entrepreneur is, globally, the one who is working, proactively, to act on its environment in such a way as to change it, to improve it.

Fonrouge (2002) agrees with the same idea, stating that simply assuming the responsibility of running a business does not necessarily make the man in question a real entrepreneur. "So it would be less the man who makes the entrepreneur than the situation, and situations would be more entrepreneurial than others." 


\subsubsection{Intrapreneur}

What is interesting to note is that there are variations of the term entrepreneur used to designate substantially different realities. Indeed, Verstraete (2000) uses the term intrapreneur to refer to a person who, although a mere employee in a company, behaves and acts like an entrepreneur.

\subsubsection{The Co-contractor}

Dokou et al. (2000) go in the same direction by designating by the term of co-entrepreneur, the collaborator of the leader of VSB who, because of his unwavering commitment with the latter, continually deploys considerable efforts by taking initiatives, by launching projects, etc.

And it is this involvement with the leader of the VSB that often predisposes the co-entrepreneur to become a full-fledged entrepreneur.

\subsubsection{The manager}

As for the term "manager" borrowed from English, it means according to the Cultural Dictionary in French: "head, manager of an enterprise; a person who exercises a management function "(Cultural Dictionary in French, T: III, Le Robert, 2005, p: 314).

The advantage of this definition lies in the fact that it specifies that today, not all managers are necessarily business leaders. They are, in fact, in many cases managers whose mission is to manage a team or a sector.

And it is often the notion of "senior manager" that is often used to evoke the mission, the level of responsibility of certain executives who are in charge of the overall or partial management of a company.

\section{BEHAVIORAL FINANCE}

In the 1980s, behavioral finance emerged as a new concept combining behavioral and psychological aspects in economic and financial decision making.

\subsection{Perspective theory}

The main assumption of the outlook theory of behavioral finance is the value function (Kahneman and Tversky, 1979). The latter introduced the point of reference which is considered to be a psychological point set by the beliefs and subjective impressions of individuals. Here, each person determines their point of reference for comparison. For example, to understand the factors of favoritism in dealing with a bank, as rational customers have their current bank's price as a point of reference when buying from a new bank.

\subsection{Regret}

People by nature tend to regret making mistakes even if they are small. It is a feeling of sadness about a bad outcome of a decision the person made earlier. If a person wants to avoid regrets, they sometimes end up not making the decision at all or making irrational decisions (Thaler, 1980).

As for cognitive dissonance which is another phenomenon that can be interpreted by the theory of regret. It is the mental stress that people experience when confronted with facts that contradict their beliefs and prove those beliefs to be wrong. It can be classified as a type of regret, regret over false beliefs and all decisions made because of those beliefs.

Also Festinger's (1962) theory asserts that people tend to take irrational measures to avoid cognitive dissonance, such as avoiding new information about their beliefs or maintaining an escape argument to protect their beliefs. While avoiding new information that contradicts one's belief and developing protective arguments can help explain the behavior of the experienced herd in Islamic finance.

\subsection{Heuristics}

Heuristics is the process that people go through to learn on their own using trial and error, which leads them to develop the Golden Rule. The problem here is that heuristics can lead to other errors (Shefrin, 2002). However, this bias can be defined as "the use of experience and practical effort to answer questions or to improve performance" as the amount of information increases and procedures become more complicated for investors in the sector. financial in general, the heuristic process is inevitable for most of them but not always successful (Fromlet, 2001).

Heuristics can be an excellent concept to explain the financial choice of investors and why they sometimes make irrational decisions, which contradicts the idea of fully informed market players. As new information circulates, different investors interpret 
this information differently depending on their heuristic rules, which can be right or wrong, generating a new learning curve and forcing them to reconsider their heuristic rules (Shefrin, 2002).

Heuristic forms are numerous, one of them being herd behavior, and this is the case when investors tend to follow the majority of individuals (Fromlet, 2001). The main line for them in making their financial decisions, for example when dealing with a specific type of bank just because there is a lot of demand, and this can lead people to make bad decisions by simply following the market trend without any rationality in this decision.

\subsection{Herd behavior}

A fundamental observation about societies is that people who interact regularly have a similar way of thinking. It is crucial to understand the cause of this correspondence in thought, to assess the reasonableness of the theories and to judge the credibility of the theory of speculative fluctuations, which claims that a fluctuation in price is due to erroneous thinking (Shefrin, 2002).

Another reason people think the same or react the same is when faced with the same information in the same situation - like dealing with a specific bank or not. The influence of the community has a significant effect on individual evaluation (Shiller, 2001). When an individual's response is different from the group's response, he tends to change his response to go with the majority, thinking "I can't be right, and all of these people are wrong"! They realize that they reacted differently to the same information statements that the majority of people got and responded in a specific way.

In everyday actions, we learn that the majority cannot be wrong if they act the same for something. This is what Shiller (2001) calls social pressure, and it has a huge influence on our decisions.

Fashion is a life example of herd behavior. While a prime example of herd behavior in the financial world is the trend of financial products linked to speculative bubbles and collisions, herd behavior is the most recognized psychological phenomenon in the financial world.

So rationality is not a metric here, as rational consumers can sometimes be a part of herd behavior when they factor in the opinions of others, even though they realize that everyone is lost in the mainstream ( Fromlet, 2001).

Moreover, if consumer behavior is rational at the individual level, it creates irrational flow behavior and creates instabilities in the market. Thaler (2005) argued that "noise trade theory" arises from the act of short-term investors in the market further affecting the behavior of long-term investors. These investors act on noise as if the noise were information giving them an advantage.

In sum, herd behavior relies heavily on "word of mouth" as people trust the media less than their family, friends and co-workers (Pound \& Shiller, 1986).

\subsection{Overconfidence}

Perhaps the most important result of a long line of psychological studies aimed at understanding market irregularities is the central behavioral phenomenon is overconfidence. People overdo it by trusting their talents and have superficial optimism about the results taking into account that they cannot control those results.

By mixing overconfidence with optimism, Kahneman and Tversky (1974) prove that people feel an overestimation of their skills and knowledge, an underestimation of risks and an exaggerated sense of the ability to control the outcome. , which leads to irrational decisions and illogical financial decisions.

Of course, overconfidence starts with trust, the greater the trust, the greater the risk of overconfidence. This appears more in areas where people are not very well informed, because this confidence is not linked to a real education (De Bondt and Thaler, 1995).

So, the relationship worth mentioning here is the relationship between overconfidence and competence. Managers who think of themselves as experts tend to overestimate the chances of success (March and Shapira, 1987), and they tend to overreact to dramatic or unexpected news (De Bondt and Thaler, 1985). Ross (1987), for example, mentioned that overconfidence is associated with greater difficulty in adequately accommodating doubt from a person's point of view.

3.6. Anchoring

It refers to the decision-making process based on quantitative assessment, where these assessments are affected by personal suggestions. Individuals have a point of reference for each financial decision (anchors), which they continue to compare to the current scenario with these points, and when they get the new information, they under-react and insufficiently shift that anchor point into depending on the news acquired (Shiller, 1989). Also anchoring is a phenomenon where people learn to focus on current scenarios and ignore historical trends.

For example, investors tend to anchor changes in one investment to changes in other investments in the market, and profit ratios of one firm may be anchored to the earnings of other firms (Shiller, 1989). 
This may explain why companies in different projects but located in the same geographic area were more prone to parallel price changes than companies in a similar project but located in a different geographic area, contradicting the expectation that the industry should drive up prices, not location (Griffin \& Karolyi, 1998).

\section{CONCLUSION}

Existing theories on capital structure do not take into account such factors as owner goals and business planning decisions, which are relevant to financing decisions. Since VSEs tend not to respond to market scrutiny, the preferences, goals and psychology of the owner-managers of these firms play an important role in capital structure decisions (Barton et al. Matthews 1989; McMahon and Stanger 1995).

In this context we introduced the theory of financial behavior as an alternative to traditional financial theories, thus to seek explanations on the processes of capital structure of VSEs by understanding the impact of personal preferences and values of owner-managers and characteristics of the company.

Matthews et al. (1994) proposed a framework in which decision-making regarding capital structure is influenced by the attitude of owners towards the usefulness of debt as a form of finance moderated by external environmental conditions, as well as by owners' needs for control, risk appetite, experience, social norms and personal net worth. Building on these perspectives, this study uses cognitive theory to examine the relevant factors that influence the choice of owner-managers of external debt.

\section{REFERENCES}

1. Michaelas, N., Chittenden, F., \& Poutziouris, P. (1999). Financial policy and capital structure choice in UK SMEs: Empirical evidence from company panel data. Small business economics, 12(2), 113-130.

2. Kahneman, D. and A. Tversky (1979), 'Prospect theory: An analysis of decisions under risk', Econometrica, 47(2): 263291.

3. Kourtidis, D., ? evi?, E., \& Chatzoglou, P. (2011). Investors' trading activity, a behavioural perspective: professionals vs. individuals. International Journal of Behavioural Accounting and Finance, 2(3-4), 346-366.

4. Beck, J. M., Ma, W. J., Kiani, R., Hanks, T., Churchland, A. K., Roitman, J., ... \& Pouget, A. (2008). Probabilistic population codes for Bayesian decision making. Neuron, 60(6), 1142-1152.

5. OCDE, 2018. LE FINANCEMENT DES PME ET DES ENTREPRENEURS 2018 : tableau de bord de l'OCDE

6. Smith, K. G., Gannon, M. J., Grimm, C., \& Mitchell, T. R. (1988). Decision making behavior in smaller entrepreneurial and larger professionally managed firms. Journal of Business Venturing, 3(3), 223-232.

7. Curran, J. and Blackburn, R. (1993), Ethnic Enterprise and the High Street Bank, Kingston Business School, Kingston University

8. Fama, E. F., \& Miller, M. H. (1972). The theory of finance. Holt Rinehart \& Winston.

9. Marchesnay M., (2003). « La petite entreprise : sortir de l'ignorance », Revue Française de Gestion, Vol 29, $\mathrm{n}^{\circ} 144, \mathrm{p}$. 107-118.

10. Lewis, V. L., \& Churchill, N. C. (1983). The five stages of small business growth. Harvard business review, 61(3), 3050 .

11. Depret, M. H., \& Hamdouch, A. (2004). La gouvernance des jeunes entreprises innovantes: un éclairage analytique à partir du cas des sociétés de biotechnologies. Finance Contrôle Stratégie, 7(2), 67-94.

12. BAM, 2018. Rapport annuel sur la supervision bancaire.

13. RADI B. \& BARI I. (2012), «les produits financiers alternatifs au Maroc : Pratique et Perspectives », La Revue des Sciences de Gestion, 2012/3 n²55-256, P : 153-159.

14. Fromlet, H. (2001) 'Behavioral Finance-Theory and Practical Application: Systematic analysis of depatures from the homo oeconomicus paradigm are essential for realistic financial research and analysis', Business Economics. Business Economics, 36(3), pp. 63-69.

15. Shefrin, H. (2002) Beyond Greed and Fear: Understanding Behavioral Finance and the Psychology of Investing, Oxford University Press. Oxford University Press. doi: 10.1093/0195161211.001.0001.

16. Shiller, R. (2001) 'Human Behaviour and the efficiency of the financial system', Cowles Foundation Papers, (N.1025), p. 37. doi: 10.3386/w6375.

17. Pound, J. and Shiller, R. (1986) Speculative Behavior of Institutional Investors. Cambridge, MA. doi: 10.3386/w1964.

18. Festinger, L. (1962) A theory of cognitive dissonance. Stanford: Stanford University

19. Thaler, R. H. (1980) 'Toward a positive theory of consumer choice', Journal of Economic Behavior \& Organization, 1, pp. 39-60. doi: 10.1016/0167- 2681(80)90051-7.

20. Thaler, R. H. (2005) Advances in behavioral finance. vol 2. Princeton University Press. 
21. De Bondt, W. F. M. and Thaler, R. H. (1995) 'Financial Decision-Making in Markets and Firms: A Behavioral Perspective', Handbooks in Operations Research and Management Science, pp. 385-410. doi: 10.1016/S09270507(05)80057-X.

22. Ross, L. (1987) 'The problem of construal in social inference and social psychology', in Neil E. Grunberg et al. (eds) A distinctive approach to psychological research: The influence of Stanley Schachter. London: Psychology Press, pp. 118150.

23. Griffin, J. M. and Karolyi, G. A. (1998) 'Another look at the role of the industrial structure of markets for international diversification strategies', Journal of Financial Economics, 50(3), pp. 351-373. doi: 10.1016/S0304-405X(98)00041-5. 